Article

\title{
Characterization of Asphalt Mixes Behaviour from Dynamic Tests and Comparison with Conventional Cyclic Tension-Compression Tests
}

\author{
Jean-Claude Carret *, Hervé Di Benedetto and Cédric Sauzéat \\ LTDS (UMR CNRS 5513), University of Lyon/ENTPE, Rue M. Audin, 69518 Vaulx en Velin, France; \\ herve.dibenedetto@entpe.fr (H.D.B.); cedric.sauzeat@entpe.fr (C.S.) \\ * Correspondence: jean-claude.carret@entpe.fr
}

Received: 16 October 2018; Accepted: 29 October 2018; Published: 1 November 2018

check for updates

Featured Application: Dynamic tests can be used to characterize asphalt mixes and the results obtained from dynamic tests are in good agreement with the results of conventional cyclic tests.

\begin{abstract}
In the presented research, conventional cyclic tension-compression tests and dynamic tests were performed on two types of asphalt mixes (AM). For the tension-compression tests, the complex modulus was obtained from the measurements of the axial stress and axial strain. For the dynamic tests, an automated impact hammer equipped with a load cell and an accelerometer were used to obtain the frequency response functions (FRFs) of the specimens at different temperatures. Two methods were proposed to back-calculate the complex modulus from the FRFs at each temperature: one using the 2S2P1D (two springs, two parabolic elements and one dashpot) model and the other considering a constant complex modulus. Then, a 2S2P1D linear viscoelastic model was calibrated to simulate the global linear viscoelastic behaviour back calculated from each of the proposed methods of analysis for the dynamic tests, and obtained from the tension-compression test results. The two methods of analysis of dynamic tests gave similar results. Calibrations from the tension-compression and dynamic tests also show an overall good agreement. However, the dynamic tests back analysis gave a slightly higher value of the norm of the complex modulus and a lower value of the phase angle compared to the tension-compression test data. This result may be explained by the nonlinearity of AM (strain amplitude is at least 100 times smaller for dynamic tests) and/or by ageing of the materials during the period between the tension-compression and the dynamic tests.
\end{abstract}

Keywords: asphalt mixes; linear viscoelasticity; complex modulus; dynamic measurements; tension-compression tests; frequency response function; back-analysis; finite element method

\section{Introduction}

Asphalt mixes (AM) have a linear viscoelastic (LVE) behaviour in the small strain domain [1] Cyclic tension-compression tests are traditionally used to determine the LVE properties of AM that are strongly dependent on frequency and temperature. However, these tests require expensive experimental devices such as hydraulic presses and are not applicable in situ. An economical alternative is to use non-destructive dynamic tests that are simple to perform and possibly adaptable for measurements on pavement structures. Impulse techniques using impact loadings [2,3] are known to provide accurate characterization of material properties in the case of elastic materials $[4,5]$. In the case of LVE materials, dynamic tests could be a great alternative to conventional cyclic tension-compression tests. Dynamic tests using wave propagation and measurement of the flying time [6-8] have been applied to LVE materials. Resonance testing considering only the fundamental 
resonance frequency [9-11] or resonant acoustic spectroscopy (RAS) [12-15] have also been applied to AM but it is not possible to describe accurately the frequency dependency behaviour of AM with these different tests. Recently, measurement of frequency response functions (FRFs) have been performed on LVE materials $[16,17]$ and more specifically on AM [18-21]. Gudmarsson et al. $[19,20]$ and Carret et al. [21] showed that using FRFs measurements to derive the LVE properties of AM is a very promising approach. However, characterizing accurately the LVE behaviour of AM from FRFs is not possible through a simplified analysis [22] and it requires an elaborate approach. In this paper, two different methods using finite element calculations are proposed to obtain the LVE behaviour from FRFs. The first method consists in an optimization of the continuous spectrum 2S2P1D (two springs, two parabolic elements and one dashpot) model constants to back-calculate the complex modulus at each tested temperature while the second method is a more direct back-calculation of the complex modulus at the first resonance frequency. The two methods were applied to two different types of AM representing five specimens that were tested with cyclic tension-compression tests and with dynamic tests. Experimental complex modulus values obtained from tension-compression tests and back-calculated from FRFs with the two proposed methods were used to fit the 2S2P1D model and the Williams-Landel-Ferry (WLF) constants simulating the global LVE behaviour of the material in each case. First, the materials tested in this study are presented. Then, the LVE behaviour characterization with cyclic tests and the modelling with the 2S2P1D model are introduced. Next, dynamic tests are introduced and the two proposed back-analysis methods are explained. Finally, data from tension-compression tests are compared with results from the two methods of back-analysis of the dynamic tests.

\section{Materials and Methods}

Two different types of AM are considered in this paper. The first material is a warm mix that was fabricated in laboratory using bitumen foam and labelled WF for warm foam. It contains $70 \%$ of reclaimed asphalt pavement (RAP) after one cycle of recycling. This material was used in a project from the French national research agency called IMPROVMURE [23]. Three specimens of this material were tested with tension-compression and dynamic tests. The second material is a mix with an optimized granular skeleton also fabricated in laboratory and labelled GB5. It contains $30 \%$ of RAP and the bitumen used is a polymer modified bitumen (PMB). Two specimens of this material were tested with tension-compression tests and dynamic tests. Table 1 gives some indications on the five studied specimens. The tension-compression tests were performed first and the dimensions listed in Table 1 correspond to the dimensions after the specimens were cut (see Section 3.1) before performing the dynamic tests.

Table 1. Specimens used in this study.

\begin{tabular}{cccccccc}
\hline Specimen & Mass (g) & $\begin{array}{c}\text { Height } \\
(\mathbf{m m})\end{array}$ & $\begin{array}{c}\text { Diameter } \\
(\mathbf{m m})\end{array}$ & $\begin{array}{c}\text { Density } \\
\left(\mathbf{k g} / \mathbf{m}^{\mathbf{3}}\right)\end{array}$ & $\begin{array}{c}\text { Void Ratio } \\
\mathbf{( \% )}\end{array}$ & $\begin{array}{c}\text { Bitumen Content } \\
\mathbf{( \% )}\end{array}$ & $\begin{array}{c}\text { RAP Content } \\
\mathbf{( \% )}\end{array}$ \\
\hline WF-4 & 1293 & 0.123 & 75 & 2379 & 6.6 & 5.4 & 70 \\
WF-6 & 1320 & 0.123 & 75 & 2431 & 4.2 & 5.4 & 70 \\
WF-8 & 1330 & 0.123 & 75 & 2449 & 3.8 & 5.4 & 70 \\
GB5-3 & 941 & 0.152 & 64 & 2381 & 4.8 & 4.8 & 30 \\
GB5-4 & 951 & 0.152 & 64 & 2378 & 5.1 & 4.8 & 30 \\
\hline
\end{tabular}

\section{Characterization of the Linear Viscoelastic (LVE) Behaviour}

\subsection{Cyclic Tension-Compression Tests}

Cyclic tension-compression tests were first performed to determine the complex modulus and complex Poisson's ratio of the five considered cylindrical specimens. A hydraulic press was used in strain-controlled mode to apply cyclic sinusoidal axial loadings with an amplitude of around $50 \mu \mathrm{m} / \mathrm{m}$. The axial stress $\sigma_{\mathrm{z}}$ was measured with a load cell, the axial strain $\varepsilon_{\mathrm{z}}$ was obtained from the average of 
three extensometers placed at $120^{\circ}$ from each other, and the radial strain $\varepsilon_{\mathrm{r}}$ was derived from the measurements of two non-contact sensors. The procedure developed at ENTPE/University of Lyon laboratory is detailed in other publications [24-26]. The complex notation of the axial stress, the axial strain and the radial strain are given in Equation (1):

$$
\begin{gathered}
\sigma_{\mathrm{z}}^{*}=\sigma_{0 \mathrm{z}} \cdot \mathrm{e}^{\mathrm{j} \omega \mathrm{t}} \\
\varepsilon_{\mathrm{z}}^{*}=\varepsilon_{0 \mathrm{z}} \cdot \mathrm{e}^{\mathrm{j}\left(\omega \mathrm{t}+\varphi_{\varepsilon \mathrm{z}}\right)} \\
\varepsilon_{\mathrm{r}}^{*}=\varepsilon_{0 \mathrm{r}} \cdot \mathrm{e}^{\mathrm{j}\left(\omega \mathrm{t}+\varphi_{\varepsilon \mathrm{r}}\right)}
\end{gathered}
$$

where $\omega$ is the pulsation ( $\omega=2 \pi f$, where $f$ is the frequency), $\sigma_{0 z}$ is the norm of the complex axial stress and $\varepsilon_{0 z}$ and $\varphi_{\varepsilon z}$ (respectively, $\varepsilon_{0 \mathrm{r}}$ and $\varphi_{\varepsilon \mathrm{r}}$ ) are the norm and phase angle of the complex axial strain (respectively, complex radial strain). The tension-compression tests were performed at eight loading frequencies $(0.003,0.01,0.03,0.1,0.3,1,3$ and $10 \mathrm{~Hz})$ and nine temperatures from $-25^{\circ} \mathrm{C}$ to $55^{\circ} \mathrm{C}$ in steps of $10^{\circ} \mathrm{C}$. Details of the experimental set up are shown in Figure 1. The complex modulus (respectively, complex Poisson's ratio) are defined as the ratio between the axial stress and the axial strain (respectively, the opposite of the radial strain and the axial strain) and they are calculated at each temperature and frequency as follow:

$$
\begin{gathered}
\mathrm{E}^{*}=\frac{\sigma_{\mathrm{z}}^{*}}{\varepsilon_{\mathrm{Z}}^{*}}=\left|\mathrm{E}^{*}\right| \cdot \mathrm{e}^{\mathrm{j} \varphi_{\mathrm{E}}} \\
v^{*}=-\frac{\varepsilon_{\mathrm{r}}^{*}}{\varepsilon_{\mathrm{Z}}^{*}}=\left|v^{*}\right| \cdot \mathrm{e}^{\mathrm{j} \varphi_{v}}
\end{gathered}
$$

where $\mathrm{E}^{*}$ is the complex modulus, $\varphi_{\mathrm{E}}$ is the phase angle of the complex modulus, $\nu^{*}$ is the complex Poisson's ratio and $\varphi_{v}$ is the phase angle of the complex Poisson's ratio.

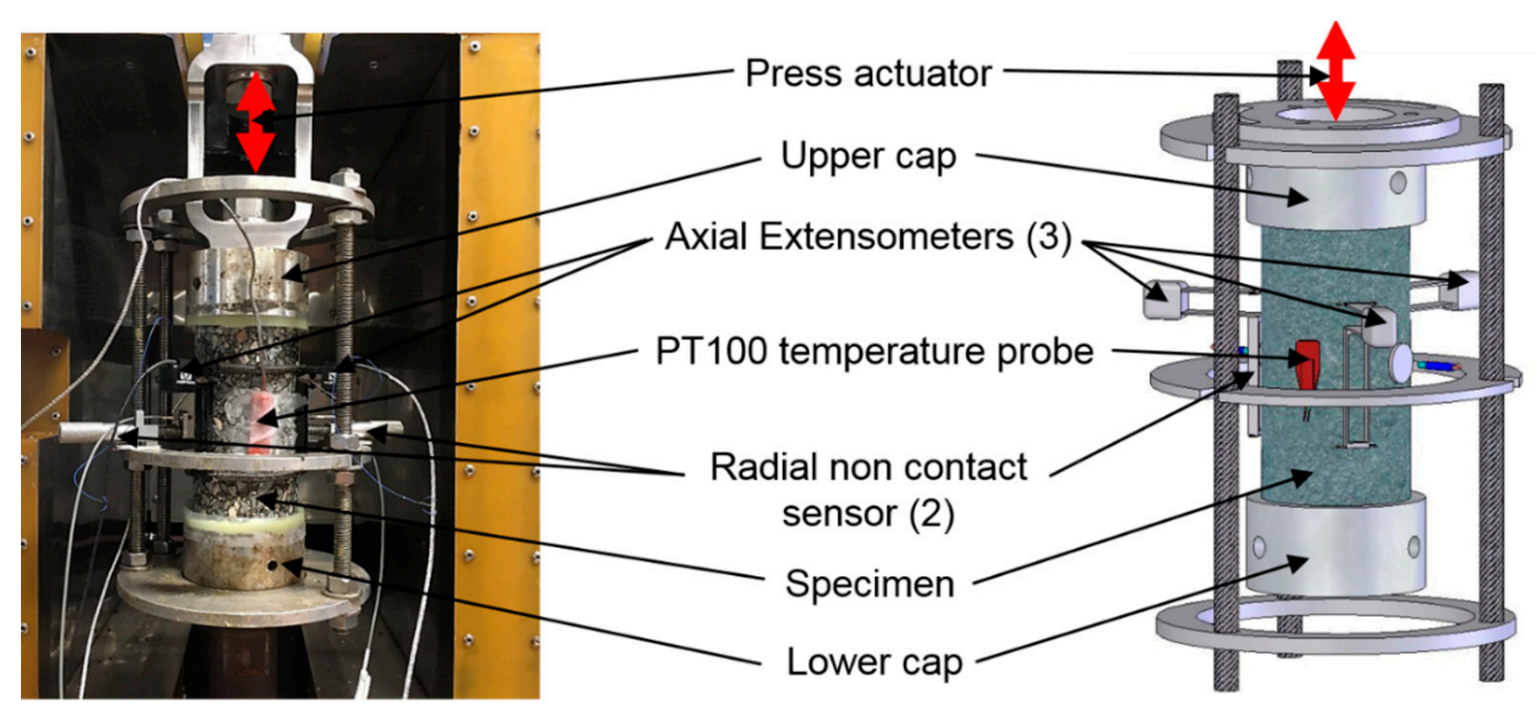

Figure 1. Tension-compression test set-up (ENTPE laboratory, University of Lyon).

\subsection{Modelling of the LVE Behaviour: 2S2P1D Rheological Model}

The continuous spectrum 2S2P1D model developed at ENTPE [27-29] was used to model the LVE behaviour of AM. This model is the association in series of two springs, two parabolic creep elements and one dashpot. In the three-dimension case [30], the expressions of the complex modulus and the complex Poisson's ratio, for isotropic behaviour, are given at a given reference temperature (Tref), by Equations (4) and (5), respectively. 


$$
\begin{aligned}
& E_{2 S 2 P 1 D}^{*}(\omega)=E_{00}+\frac{E_{0}-E_{00}}{1+\delta\left(j \omega \tau_{E}\right)^{-k}+\left(j \omega \tau_{E}\right)^{-h}+\left(j \omega \beta \tau_{E}\right)^{-1}} \\
& v_{2 S 2 P 1 D}^{*}(\omega)=v_{00}+\frac{v_{0}-v_{00}}{1+\delta\left(j \omega \tau_{v}\right)^{-k}+\left(j \omega \tau_{v}\right)^{-h}+\left(j \omega \beta \tau_{v}\right)^{-1}}
\end{aligned}
$$

where $\omega$ is the pulsation ( $\omega=2 \pi f$, where $\mathrm{f}$ is the frequency), $E_{0}$ and $v_{0}$ are the high frequency modulus and Poisson's ratio, $\mathrm{E}_{00}$ and $v_{00}$ are the low frequency modulus and Poisson's ratio, $\mathrm{k}$ and $\mathrm{h}$ are dimensionless constants such as $0<\mathrm{k}<\mathrm{h}<1, \delta$ is a dimensionless constant, and $\beta$ is a dimensionless constant related to Newtonian viscosity $\eta$ by $\eta=\left(E_{0}-E_{00}\right) \beta \tau_{E} . \tau_{E}$ and $\tau_{v}$ are characteristic time constants of the complex modulus and Poisson's ratio linked by a constant ratio. The values of the characteristic times vary only with temperature. The time temperature superposition principle (TTSP) is verified for asphalt mixes in the linear and nonlinear domains [31-33] so it is possible to calculate the characteristic time at any given temperature using Equation (6):

$$
\tau(\mathrm{T})=\mathrm{a}_{\mathrm{T}}(\mathrm{T}) \tau_{\mathrm{ref}}
$$

where $\tau_{\text {ref }}$ is the characteristic time at the reference temperature $\left(\tau_{\mathrm{E}}\right.$ or $\left.\tau_{v}\right)$ and $\mathrm{a}_{\mathrm{T}}$ is the shift factor at the temperature $\mathrm{T}$ defined by the Williams-Landel-Ferry (WLF) equation [34]:

$$
\log \left(\mathrm{a}_{\mathrm{T}}\right)=-\frac{\mathrm{C}_{1}\left(\mathrm{~T}-\mathrm{T}_{\mathrm{ref}}\right)}{\mathrm{C}_{2}+\mathrm{T}-\mathrm{T}_{\mathrm{ref}}}
$$

where $C_{1}$ and $C_{2}$ are the two constants of the WLF equation and $T_{\text {ref }}$ is the reference temperature.

\section{Dynamic Tests}

\subsection{Measurement of the Frequency Response Functions (FRFs)}

First, the specimens used for complex modulus tension-compression test were sawed to separate the glued upper and lower metallic caps before performing the dynamic measurements. An impact hammer equipped with a load cell (PCB model 086E80) was used as an external source of excitation. The order of magnitude of the maximum strain induced in the specimen by the impact is of about $0.1 \mu \mathrm{m} / \mathrm{m}[18,21]$. The impact hammer was automated with a solenoid piston programmed with a microcontroller (Arduino Uno R3) to improve the repeatability of the test and to allow measurements directly inside a thermal chamber. This automated system was inspired by systems previously developed by Norman et al. in 2012 and Brüggemann et al. in 2015 [35,36]. The response of the materials was recorded with an accelerometer (PCB model 353B15). The impact hammer and the accelerometer were connected to a signal conditioner (PCB model 482C15) and the signal conditioner was connected to a data acquisition device (NI USB-6356) connected to a computer. To achieve free boundary conditions, soft foam was placed under the specimens during the tests. In this study, only the longitudinal compression mode of vibrations was considered. For this mode of vibrations, the impact is applied in the centre of one short side of the cylinder while the acceleration is measured in the centre of the opposite short side. The experimental set up for the dynamic tests corresponding to the longitudinal mode of vibrations is presented in Figure 2.

The measurements were recorded with a sampling frequency of $1 \mathrm{MHz}$ by using a MATLAB application which was specifically developed for this test. Measurements were performed at five temperatures $\left(-20,0,15,35\right.$ and $\left.50^{\circ} \mathrm{C}\right)$ and five impacts were applied at each temperature. The applied force and the acceleration were recorded for each impact. The experimental data in time domain were then converted in frequency domain with a $1 \mathrm{~Hz}$ resolution using the Fast Fourier Transform (FFT). Figure 3 shows an example of the signals in time and frequency domains for specimen GB5-3 at $14.7^{\circ} \mathrm{C}$ (measured temperature with a probe at the surface of the specimen). 


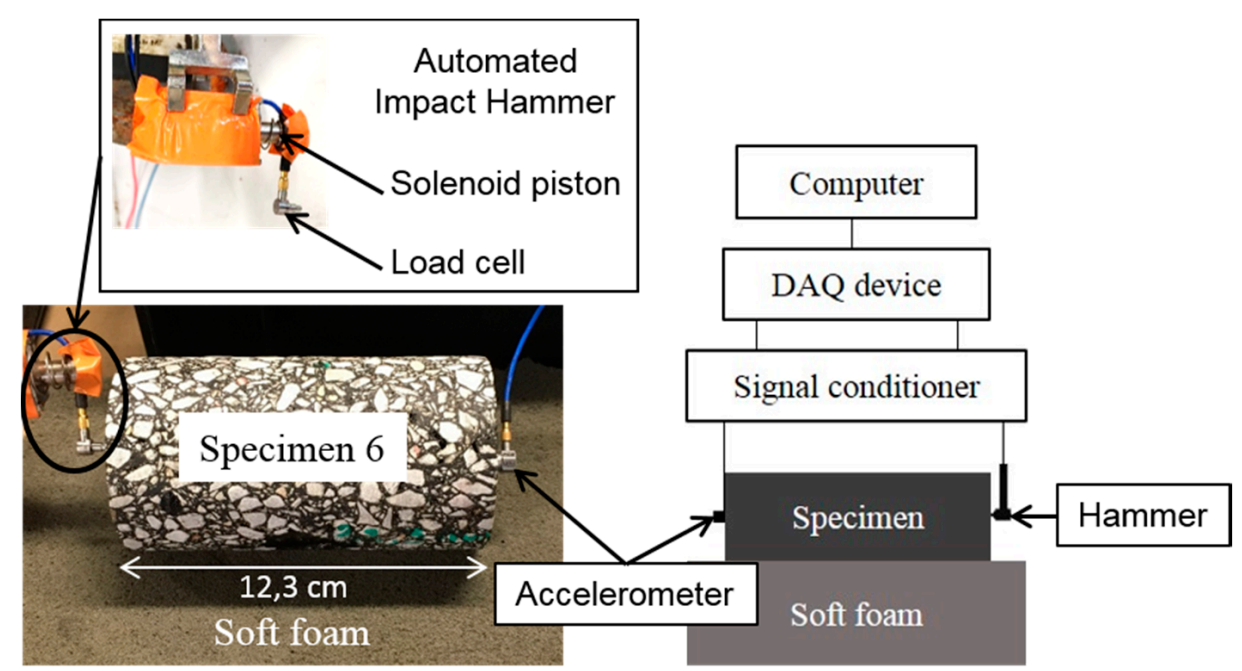

Figure 2. Test set up for the dynamic impact tests (example for specimen WF-6, ENTPE laboratory, University of Lyon).
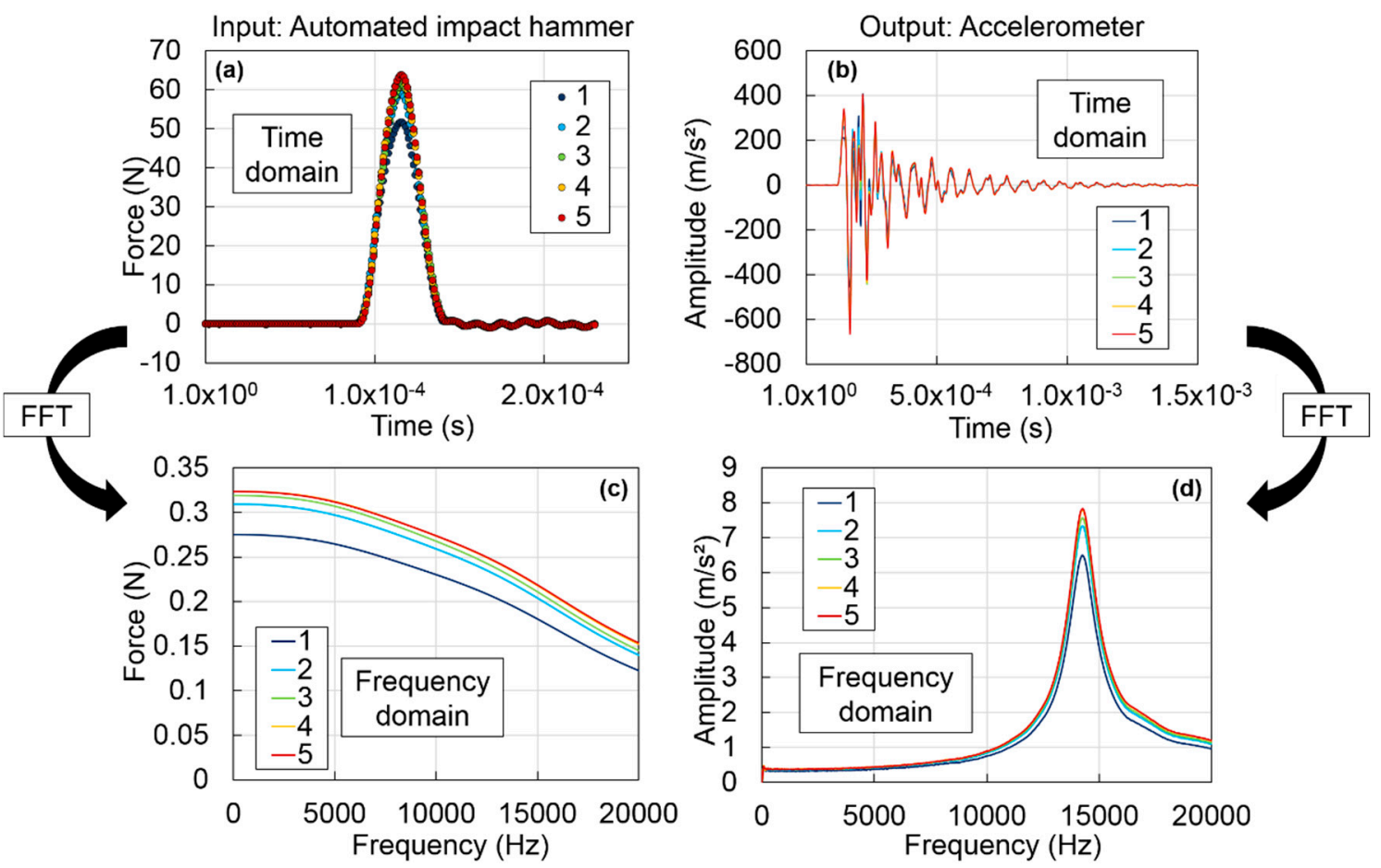

Figure 3. Dynamic test experimental data for specimen GB5-3 at $14.7^{\circ} \mathrm{C}$ (5 hits): (a) force in time domain; (b) acceleration in time domain; (c) force in frequency domain; and (d) acceleration in frequency domain.

As shown in Figure 3, the frequency spectrum of the impact contains energy up to $20 \mathrm{kHz}$, which is the maximum frequency considered for the calculations of frequency response functions (FRFs) in this study. FRFs were calculated from the frequency domain signals as follow:

$$
\mathrm{H}(\mathrm{f})=(\overline{\mathrm{Y}(\mathrm{f}) \cdot \mathrm{X} *(\mathrm{f})}) /(\overline{\mathrm{X}(\mathrm{f}) \cdot \mathrm{X} *(\mathrm{f})})
$$

where $\mathrm{H}$ is the FRF, $\mathrm{Y}$ is the FFT of the measured acceleration, $\mathrm{X}$ is the FFT of the applied force, $\mathrm{X}^{*}$ is the complex conjugate of the applied force and the bar above corresponds to the arithmetic 
average from the five impacts. The five FRFs corresponding to each of the five impacts and the averaged FRF (Equation (8)) for specimen GB5-3 at $14.7^{\circ} \mathrm{C}$ are displayed on Figure 4. Figure 4 shows that the six FRFs overlaps, which confirms the very good repeatability of the test.

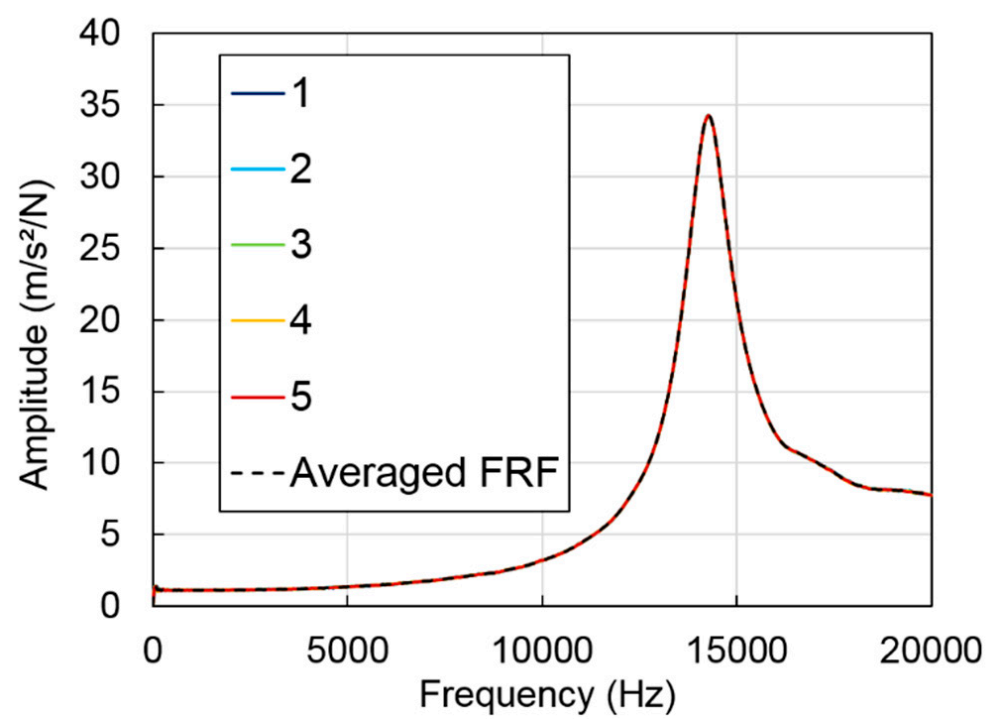

Figure 4. FRFs obtained for the 5 hits and averaged FRF (Equation (8)) of specimen GB5-3 at $14.7^{\circ} \mathrm{C}$.

Quality of the measurements was also checked with the coherence function. The coherence is a value between 0 and 1 that indicates how much of the vibratory response recorded with the accelerometer is due to the impact. For a value of 1 , the response is fully explained by the impact while decreasing values indicate that something has disrupted the test. Coherence function is calculated according to Equation (9):

$$
\mathrm{CF}(\mathrm{f})=(\overline{\mathrm{X} *(\mathrm{f}) \cdot \mathrm{Y}(f)})^{2} /((\overline{\mathrm{X}(\mathrm{f}) \cdot \mathrm{X} *(\mathrm{f})}) \cdot(\overline{\mathrm{Y}(\mathrm{f}) \cdot \mathrm{Y} *(\mathrm{f})}))
$$

where $\mathrm{CF}$ is the coherence function, $\mathrm{Y}$ and $\mathrm{Y}^{*}$ are the FFT of the measured acceleration and its complex conjugate, $\mathrm{X}$ and $\mathrm{X}^{*}$ are the FFT of the applied force and its complex conjugate and the bar above corresponds to the arithmetic average. The coherence functions of specimen GB5-3 for the five tested temperatures are presented in Figure 5. For all temperatures, the coherence function is very good with values close to one for frequencies higher than $1000 \mathrm{~Hz}$. It is therefore recommended to not use the frequencies below $1000 \mathrm{~Hz}$.
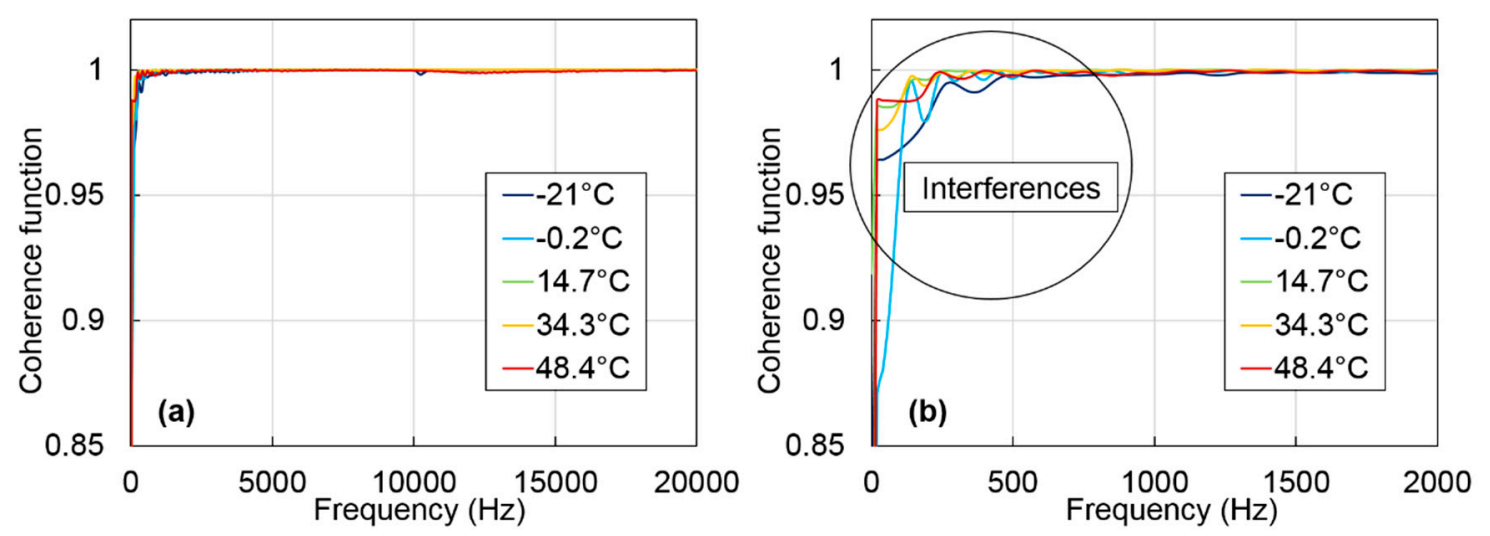

Figure 5. Coherence functions obtained for specimen GB5-3 at the five tested temperatures (a); and zoom on the lower frequencies $(\mathbf{b})$. 


\subsection{Calculation of FRFs with the Finite Element Method (FEM)}

Numerical FRFs were calculated with the finite element method (FEM) considering linear viscoelastic behaviour and the dynamic test boundary conditions. Figure 6 shows the FEM mesh and boundary conditions used for the FEM calculation of the FRFS.
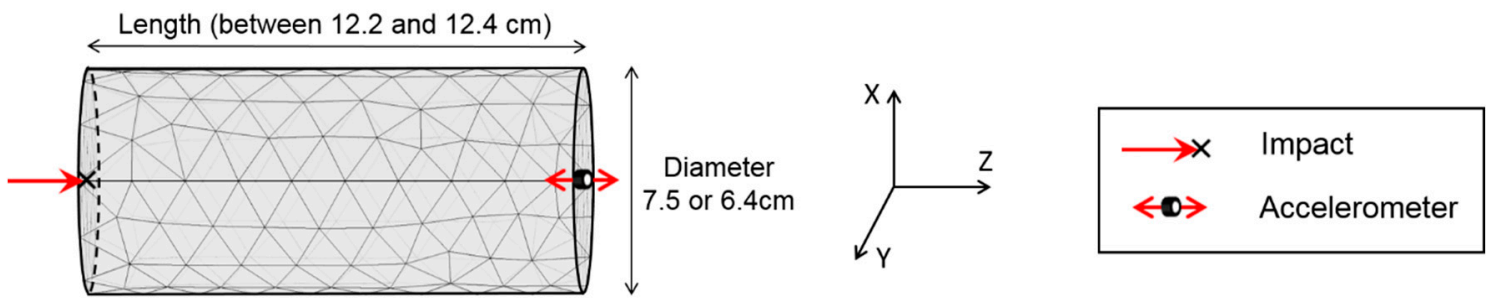

Figure 6. Finite element mesh and boundary conditions used for the FEM calculation of the FRFS.

FRFs were calculated at the desired frequencies by resolving the following three-dimensional equation of motion in frequency domain:

$$
-\rho \omega^{2} \mathbf{u}-\nabla \cdot \sigma=0
$$

where $\rho$ is the bulk density of the material, $\omega$ is the angular frequency, $\mathbf{u}$ is the displacement vector, $\nabla$ is the gradient tensor operator and $\sigma$ is the Cauchy stress tensor. Free boundary conditions are assumed to solve Equation (10) except at the impact point where a cyclic load $\mathrm{e}^{\mathrm{i} \omega \mathrm{t}}$ is applied in the direction of the impact. Since the load amplitude is unity, the calculated FRFs correspond to the calculated acceleration in direction $\mathrm{Z}$ (direction of vibration of the accelerometer in physical tests). Back analysis was performed considering two LVE behaviour models successively, as explained below.

\subsection{Determination of the Material LVE Properties from Dynamic Tests}

The LVE properties of the material were determined from the FRFs measured with the dynamic tests in two steps. The first step is a back-calculation of the complex modulus of the material at each tested temperature. Two methods, presented in the next sections, were used for this purpose. They consist in optimizing the constants of the LVE model used to calculate FRFs so that calculated FRFs match the experimental measured FRFs using dynamic tests at the considered temperature. The second step, which is the same for the two proposed methods, consists in using the complex modulus values determined in the first step at each temperature to fit a 2S2P1D model and a WLF law simulating the global LVE behaviour of the material. This operation is similar to what is done with the tension-compression test data.

\subsubsection{First Method: Optimization of the 2S2P1D Model Constants to Match Experimental FRFs}

Among the 10 constants of the 2S2P1D model, only four constants $\left(E_{0}, k, \delta\right.$ and $\left.\tau_{E}\right)$ have a significant influence for the considered range of frequencies involved during dynamic tests and need to be optimized. The complex Poisson's ratio has a very small influence on the calculation of the FRFs below $20 \mathrm{kHz}$. Poisson's ratio cannot be back-calculated with this procedure; however, it is necessary to assume values for constants $v_{00}, v_{0}$ and $\tau_{v}$ to back-calculate the complex modulus at each temperature. For each tested temperature, the vector $X$ of the four constants $\left(E_{0}, k, \delta\right.$ and $\left.\tau_{E}\right)$ to be identified was optimized iteratively so that the calculated FRFs match the experimental FRFs. The values of the six other constants were fixed to classical values for $\mathrm{AM}$ : $\mathrm{E}_{00}=100 \mathrm{MPa}, v_{0}=0.19, v_{00}=0.45, \mathrm{~h}=0.53$, $\beta=250$ and $\tau_{v}=31.6 \tau_{\mathrm{E}}$. Only the values of the experimental FRFs at frequencies around the resonance frequencies are used as input in the optimization according to previous studies [19-21] that showed 
their meaningful importance. Ten frequencies were selected along each resonance peak and the error function to minimize was defined as follow:

$$
\text { Error }=\sum_{\mathrm{j}=1}^{N \text { peaks }} \sum_{\mathrm{i}=1}^{10}\left(\left|\frac{\left|\mathrm{H}_{\operatorname{Exp}_{j i}}\right|-\left|\mathrm{H}_{\mathrm{C}_{j i}}\right|}{\left|\mathrm{H}_{\text {Exp }}\right|}\right|\right)
$$

where $\mathrm{H}_{\operatorname{Exp}}$ is the experimental FRF, $\mathrm{H}_{\mathrm{C}}$ is the calculated FRF, $\mathrm{N}_{\text {peaks }}$ is the number of resonance peaks, $j$ is the index of the peak and $i$ is the index of the frequencies. The number of peaks considered for the optimization at each temperature corresponds to the number of peaks that are visible below $20 \mathrm{kHz}$ (maximum considered frequency with our experimental device). This number is given in Table 2 for each temperature.

Table 2. Number of peaks considered for the optimization of the 2S2P1D model constants at each temperature.

\begin{tabular}{lccccc}
\hline Temperature $\left({ }^{\circ} \mathrm{C}\right)$ & $\mathbf{- 2 0}$ & $\mathbf{0}$ & $\mathbf{1 5}$ & $\mathbf{3 5}$ & $\mathbf{5 0}$ \\
\hline Number of peaks & 1 & 1 & 1 & 1 & 2 \\
\hline
\end{tabular}

The optimization was performed in MATLAB with the "fminsearch" algorithm and the optimization was stopped when the error and the parameter tolerance of $1 \%$ is reached (e.g., when the variation of the error and of all the values of the four constants to be identified is less than $1 \%$ between two iterations of the algorithm). The final vector $X_{f}$ of the four constants $\left(E_{0}, k, \delta\right.$ and $\left.\tau_{E}\right)$ was then used with the three fixed constants related to the complex modulus $\left(E_{00}, h\right.$, and $\left.\beta\right)$ to back-calculate the complex modulus at the resonance frequencies of the peaks used as input for the optimization at the considered temperature. The optimization procedure to identify the four 2S2P1D model constants $\left(E_{0}, k, \delta\right.$ and $\left.\tau_{E}\right)$ at each temperature is explained in Figure 7.

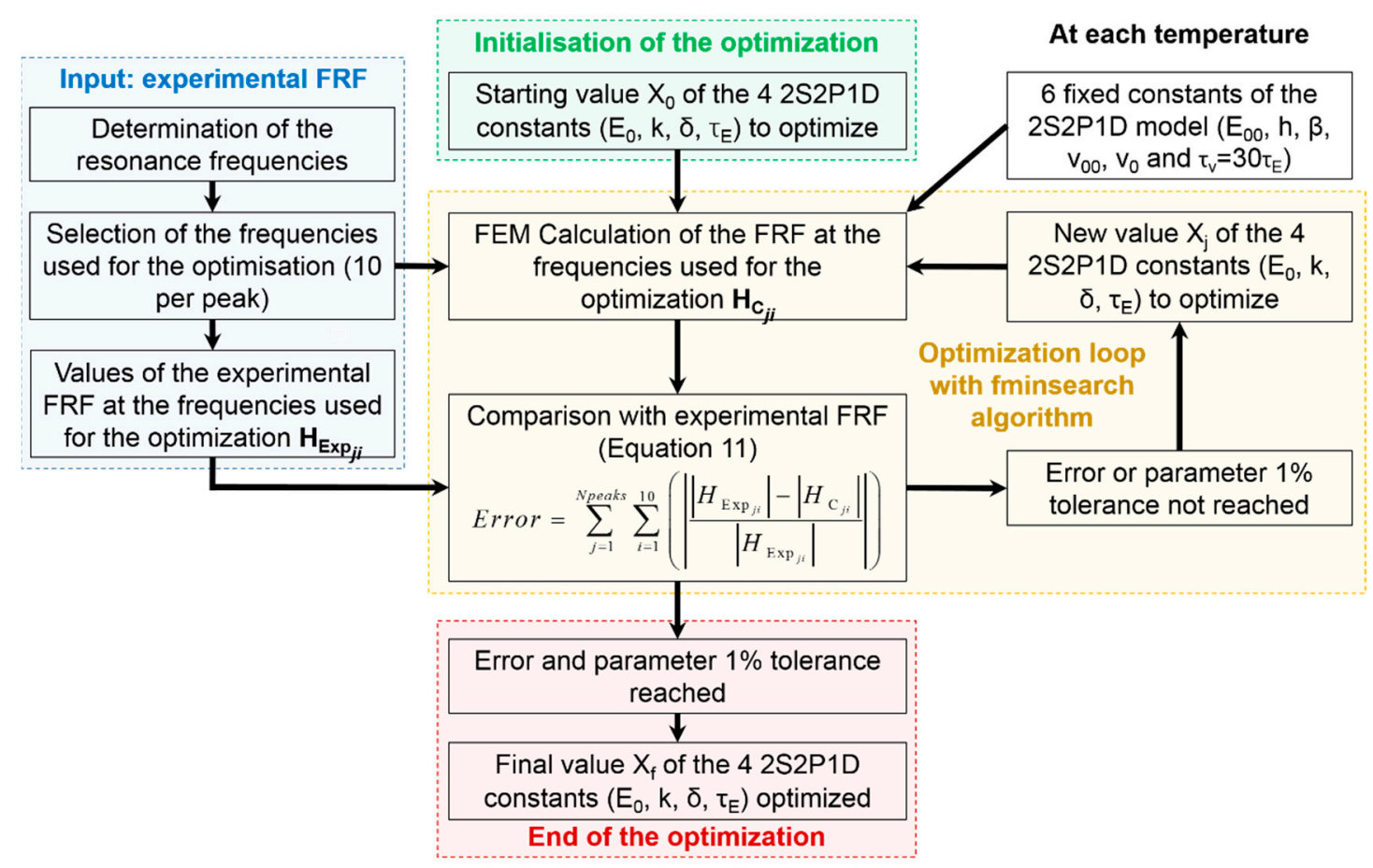

Figure 7. Method 1: Principle of the optimization procedure to identify the four 2S2P1D constants $\left(E_{0}, k, \delta\right.$ and $\left.\tau_{E}\right)$ at each temperature. $X_{f}$ is the final vector of the four 2S2P1D constants to identify. 


\subsubsection{Second Method: Constant Complex Modulus Obtained from the First Resonance Peak Only}

The second method is a simplified approach that does not require, in the first step, a rheological LVE model considering the frequency and temperature dependence. At each tested temperature, a constant complex modulus value and a constant real Poisson's ratio of 0.3 were considered. A numerical sensitivity analysis was performed to evaluate the influence of the norm and phase angle of the complex modulus and the real value of the Poisson's ratio on the calculation of FRFs. The influence of each LVE constant was evaluated from FRFs calculated for five values taken in the range of variation of the considered LVE constant while the two others are fixed. Table 2 lists the five values considered for each LVE constant and the corresponding fixed values of the two others. Some results are shown on Figure 8 for a cylinder with similar dimensions than those used in this study and with a density of $2400 \mathrm{~kg} / \mathrm{m}^{3}$. It is shown in Figure 8 that the norm of the complex modulus has an important influence on the first resonance frequency but not on the amplitude. It is the reverse for the phase of the complex modulus, while Poisson's ratio has little influence on both the frequency and the amplitude.
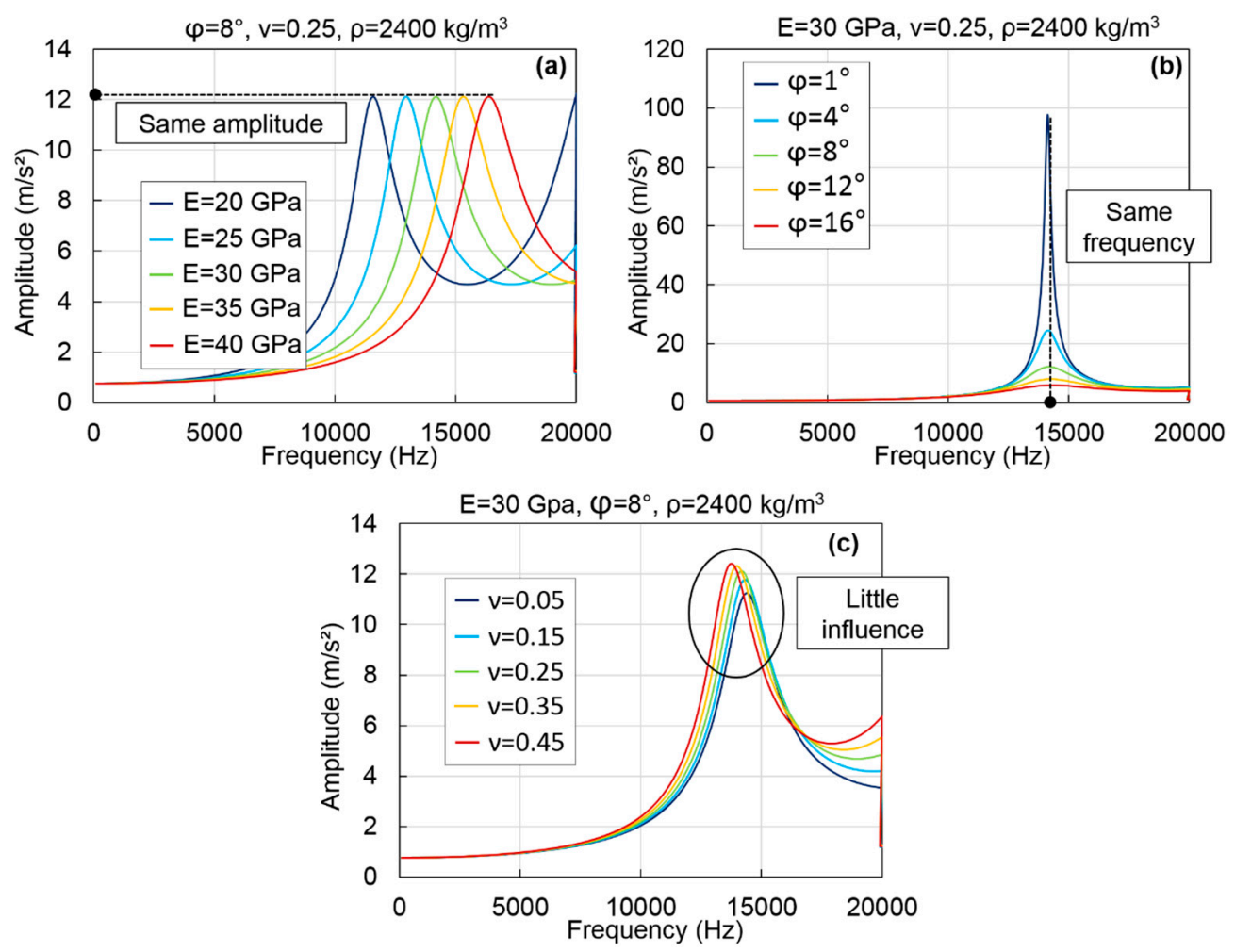

Figure 8. Influence of: $\mathrm{E}(\mathbf{a}) ; \varphi(\mathbf{b})$; and $v(\mathbf{c})$ on the first peak of the FRFs corresponding to the first resonance (example of calculations for a cylinder with a $7.5 \mathrm{~cm}$ diameter and a $12.3 \mathrm{~cm}$ length).

To confirm the observation raised in Figure 8, the relative standard deviations (RSD) for the first resonance frequency and amplitude were calculated for the three studied constants. Results are given in Table 3. They confirm the previous observations and also indicate that the norm of the complex modulus has really no impact on the peak amplitude while the phase has a very little influence on the frequency. The Influence of the Poisson's ratio can be considered as negligible when compared with the influence of the two other constants. Observations presented in Figure 8 and Table 3 justify the assumption of a constant real value of 0.3 for the Poisson's ratio. In addition, the identification of the norm and phase of the complex modulus can be separated into two steps: the norm can be determined by dichotomy from the first resonance frequency and then the phase can be determined by dichotomy from the corresponding amplitude. This process was repeated iteratively until the error on 
the amplitude is less than $0.1 \%$. Figure 9 shows the principle of the back-calculation of the complex modulus using the first resonance peak of the FRFs.

Table 3. Influence of $\mathrm{E}, \varphi$ and $v$ on the first resonance frequency and FRF amplitude. When one of the constants varies, the two other constants are fixed at the values listed in the left column.

\begin{tabular}{cccccccc}
\hline & E (GPa) & $\mathbf{2 0}$ & $\mathbf{2 5}$ & $\mathbf{3 0}$ & $\mathbf{3 5}$ & $\mathbf{4 0}$ & RSD (\%) \\
\hline $\boldsymbol{\varphi}=\mathbf{8}^{\circ}$ & $\mathrm{f}(\mathrm{Hz})$ & 11,580 & 12,940 & 14,180 & 15,320 & 16,380 & 13.5 \\
$\boldsymbol{v}=\mathbf{0 . 2 5}$ & Amplitude $\left(\mathrm{m} / \mathrm{s}^{2}\right)$ & 12.1 & 12.1 & 12.1 & 12.1 & 12.1 & $6 \times 10^{-4}$ \\
\hline $\mathbf{E}=\mathbf{3 0 ~ G P a}$ & $\mathrm{f}(\mathrm{Hz})$ & 14,120 & 14,140 & 14,180 & 14,240 & 14,340 & 0.6 \\
$\boldsymbol{v}=\mathbf{0 . 2 5}$ & Amplitude $\left(\mathrm{m} / \mathrm{s}^{2}\right)$ & 97.7 & 24.4 & 12.1 & 8.0 & 5.9 & 130.8 \\
\hline & $\boldsymbol{v}$ & $\mathbf{0 . 0 5}$ & $\mathbf{0 . 1 5}$ & $\mathbf{0 . 2 5}$ & $\mathbf{0 . 3 5}$ & $\mathbf{0 . 4 5}$ & $\mathbf{R S D}(\mathbf{\%})$ \\
\hline $\mathbf{E}=\mathbf{3 0 ~ G P a}$ & $\mathrm{f}(\mathrm{Hz})$ & 14,400 & 14,320 & 14,180 & 13,980 & 13,760 & 1.8 \\
$\boldsymbol{\varphi}=\mathbf{8}^{\circ}$ & Amplitude $\left(\mathrm{m} / \mathrm{s}^{2}\right)$ & 11.2 & 11.8 & 12.1 & 12.3 & 12.4 & 4.0 \\
\hline
\end{tabular}

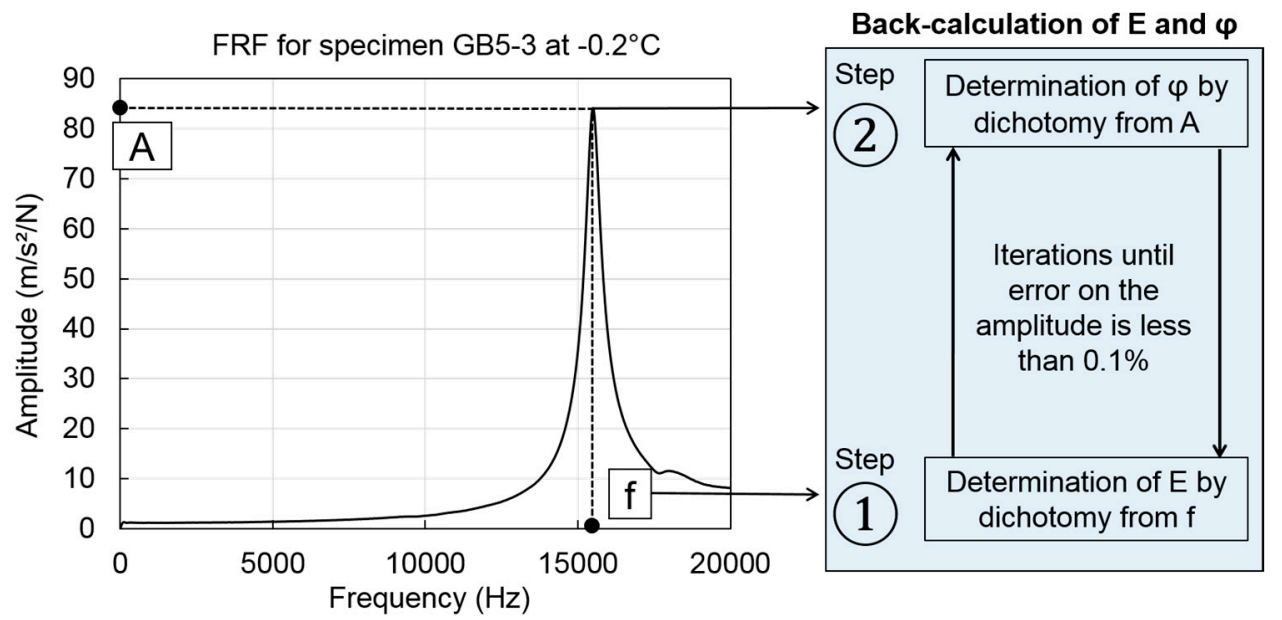

Figure 9. Method 2: Principle of the back-calculation of the complex modulus on the first resonance peak at each temperature (example for specimen GB5-3 at $-0.2^{\circ} \mathrm{C}$ ).

\subsubsection{Summary and Remarks on the Two Methods}

Differences between the two proposed methods concern the first step in which the complex modulus is back-calculated at each temperature, while the second step is identical for the two methods. First, the assumptions on the Poisson's ratio value are different in the two methods. In the first method, the Poisson's ratio is a complex number, which depends on the frequency and on the temperature, and is modelled with the 2S2P1D model assuming the values of constants $v_{00}, v_{0}$ and $\tau_{E} / \tau_{v}$. In the second method, a constant real value of Poisson's ratio equal to 0.3 is assumed. Another difference is that all resonance peaks under $20 \mathrm{kHz}$ are considered in the first method while only the first resonance peak is used in the second method. Consequently, the second method gives only one value of the complex modulus at each temperature while the first method gives values for each resonance frequency. This difference is not essential in this study since $50^{\circ} \mathrm{C}$ is the only temperature for which two peaks were observed. However, it can be interesting to evaluate more than one value of the complex modulus at each temperature. Finally, in the first method, four constants are evaluated at each temperature using a complex algorithm. In the second method, only two constants are evaluated using a simple dichotomy process. The second method is therefore very easy to apply and time-effective compared to the first method. Figure 10 highlights the main differences between the first step of the two methods and gives the principle of the second step that is identical for the two methods. Note that, even though the same constant $\mathrm{h}$ is fixed for the back-calculation at each temperature (in the first 
step of first method), a different constant $\mathrm{h}$ value can be obtained during the calibration process of the second step.

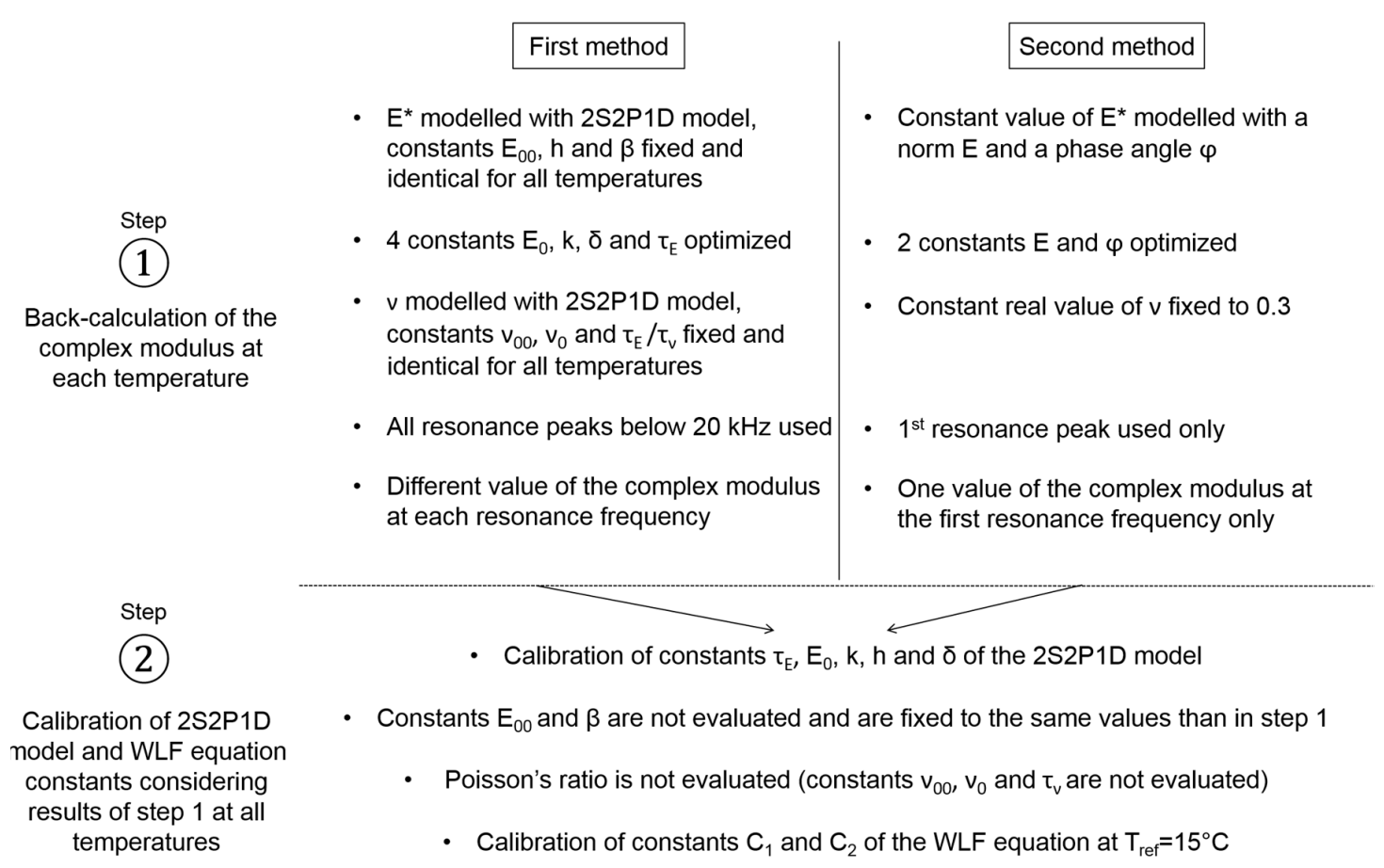

Figure 10. Summary and differences between the two proposed methods of back-analysis of the dynamic tests.

\section{Results}

\subsection{Tension-Compression Tests Results}

Results of the tension-compression tests for specimen WF-8 are plotted in Figure 11. A continuous curve can be seen on the Cole-Cole diagram, which indicates that the material is rheologically simple and that the time-temperature superposition principle (TTSP) is valid. The master curve of the norm of the complex modulus is plotted at a reference temperature $\left(\mathrm{T}_{\text {ref }}\right)$ of $15^{\circ} \mathrm{C}$ in Figure 11. The 2S2P1D model was fitted to the experimental data and is also plotted in Figure 11. A very good agreement between the experimental data and the 2S2P1D model can be observed.
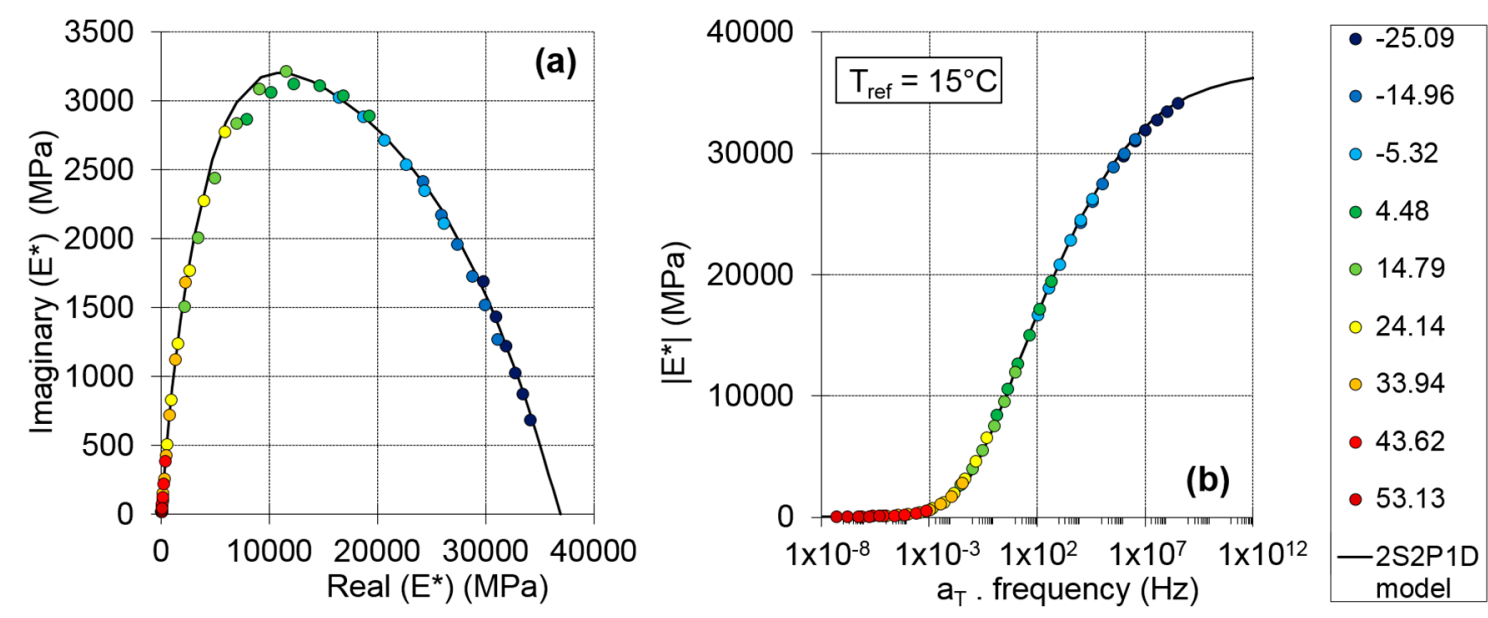

Figure 11. Tension-compression test results and fitted 2S2P1D model for specimen WF-8: (a) Cole-Cole diagram; and (b) master curve for the norm of the complex modulus at $15^{\circ} \mathrm{C}$. 
The values of the 2S2P1D model and WLF equation constants obtained from the tension-compression tests are given for all specimens in Table 4 . The constants $k, h, \delta, \beta, C_{1}$ and $C_{2}$ have the same values for a given material because they are only depending on the bitumen and not on the granular skeleton as shown in previous research $[27,37,38]$.

Table 4. Calibrated 2S2P1D constants to match tension-compression measurements.

\begin{tabular}{cccccccccc}
\hline Specimen & $\mathbf{E}_{\mathbf{0 0}} \mathbf{( M P a )}$ & $\mathbf{E}_{\mathbf{0}} \mathbf{( M P a )}$ & $\boldsymbol{\delta}$ & $\mathbf{k}$ & $\mathbf{h}$ & $\boldsymbol{\beta}$ & $\boldsymbol{\tau}_{\mathrm{E} 1 \mathbf{5}^{\circ} \mathbf{C}}(\mathbf{s})$ & $\mathbf{C}_{\mathbf{1}}$ & $\mathbf{C}_{\mathbf{2}}$ \\
\hline WF-4 & 28 & 33,400 & 2.28 & 0.177 & 0.57 & 154 & $5.4 \times 10^{-2}$ & 24.9 & 166.6 \\
WF-6 & 40 & 37,500 & 2.28 & 0.177 & 0.57 & 154 & $7.0 \times 10^{-2}$ & 24.9 & 166.6 \\
WF-8 & 56 & 36,900 & 2.28 & 0.177 & 0.57 & 154 & $6.9 \times 10^{-2}$ & 24.9 & 166.6 \\
GB5-3 & 65 & 39,100 & 1.80 & 0.180 & 0.60 & 350 & $7.5 \times 10^{-2}$ & 24.7 & 165.9 \\
GB5-4 & 65 & 39,500 & 1.80 & 0.180 & 0.60 & 350 & $1.5 \times 10^{-1}$ & 24.7 & 165.9 \\
\hline
\end{tabular}

The measurements were recorded with a sampling frequency of $1 \mathrm{MHz}$ by using a MATLAB application which was specifically developed for this test. Measurements were performed at five temperatures $\left(-20,0,15,35\right.$ and $\left.50^{\circ} \mathrm{C}\right)$ and five impacts were applied at each temperature. The applied force and the acceleration were recorded for each impact. The experimental data in time domain were then converted in frequency domain with a $1 \mathrm{~Hz}$ resolution using the Fast Fourier Transform (FFT). Figure 3 shows an example of the signals in time and frequency domains for specimen GB5-3 at $14.7^{\circ} \mathrm{C}$ (measured temperature with a probe at the surface of the specimen).

\subsection{Dynamic Impact Tests Results}

The complex modulus values back-calculated at each temperature from the FRFs measurements with the two proposed methods for specimen WF-8 are plotted, as an example, in Figure 12. For the first method of back-calculation, one value of the complex modulus is plotted for temperatures at which only one peak was considered for the optimization $\left(-20,0,15\right.$ and $\left.35^{\circ} \mathrm{C}\right)$ and two values are plotted at $-50^{\circ} \mathrm{C}$ because two peaks exist for this temperature. Only one value of the complex modulus is presented for each temperature for Method 2 because the back-calculation is limited to the first resonance frequency, as explained previously. The master curve of the norm of the complex modulus at $15{ }^{\circ} \mathrm{C}$ was obtained considering the validity of the TTSP. The 2S2P1D model was fitted to the back-calculated modulus for both methods and the two resulting 2S2P1D model curves are also plotted in Figure 12. Good fitting of the 2S2P1D curves can be observed for both methods, which give only slightly different results.
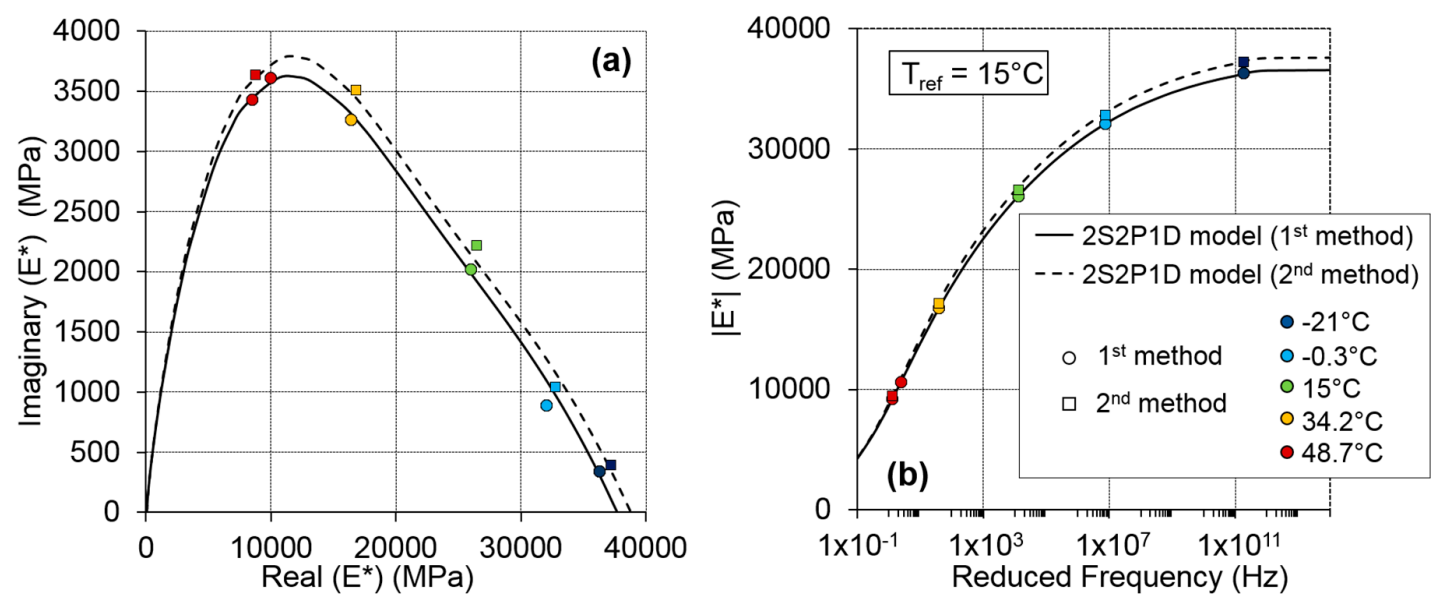

Figure 12. Dynamic test results and fitted 2S2P1D model curve for the two analysis methods for specimen WF-8: (a) Cole-Cole diagram; and (b) master curve for the norm of the complex modulus at $15^{\circ} \mathrm{C}$. 
The values of the 2S2P1D model and WLF equation constants fitting the results from the two back-analysis methods are given for all specimens in Table 5 (first method) and Table 6 (second method). Note that similarly to the results of the tension-compression tests, constants $k, h, \delta, \beta, C_{1}$ and $C_{2}$ have the same values for a given material. In addition, the same WLF equation constants can be used for the two methods and only constant $\mathrm{E}_{0}$ differs between the first and the second method.

Table 5. Calibrated 2S2P1D constants to match complex modulus back-calculated from dynamic tests with the first method using 2S2P1D model at each temperature. Constants $\mathrm{E}_{00}$ and $\beta$ are assumed to be $100 \mathrm{MPa}$ and 250, respectively.

\begin{tabular}{cccccccccc}
\hline Specimen & $\mathbf{E}_{\mathbf{0 0}} \mathbf{( M P a )}$ & $\mathbf{E}_{\mathbf{0}} \mathbf{( M P a )}$ & $\boldsymbol{\delta}$ & $\mathbf{k}$ & $\mathbf{h}$ & $\boldsymbol{\beta}$ & $\boldsymbol{\tau}_{\mathrm{E} 1 \mathbf{5}^{\circ} \mathbf{C}} \mathbf{( s )}$ & $\mathbf{C}_{\mathbf{1}}$ & $\mathbf{C}_{\mathbf{2}}$ \\
\hline WF-4 & 100 & 34,800 & 1.39 & 0.142 & 0.49 & 250 & $4.0 \times 10^{-2}$ & 18.9 & 133.2 \\
WF-6 & 100 & 38,700 & 1.39 & 0.142 & 0.49 & 250 & $7.0 \times 10^{-2}$ & 18.9 & 133.2 \\
WF-8 & 100 & 37,500 & 1.39 & 0.142 & 0.49 & 250 & $4.0 \times 10^{-2}$ & 18.9 & 133.2 \\
GB5-3 & 100 & 39,100 & 1.17 & 0.130 & 0.442 & 250 & $5.5 \times 10^{-2}$ & 19.2 & 139.5 \\
GB5-4 & 100 & 40,500 & 1.17 & 0.130 & 0.442 & 250 & $7.0 \times 10^{-2}$ & 19.2 & 139.5 \\
\hline
\end{tabular}

Table 6. Calibrated 2S2P1D constants to match complex modulus back-calculated from dynamic tests measurements with the second method using the first resonance peak at each temperature. Constants $\mathrm{E}_{00}$ and $\beta$ are assumed to be $100 \mathrm{MPa}$ and 250, respectively.

\begin{tabular}{cccccccccc}
\hline Specimen & $\mathbf{E}_{\mathbf{0 0}} \mathbf{( M P a )}$ & $\left.\mathbf{E}_{\mathbf{0}} \mathbf{( M P a}\right)$ & $\boldsymbol{\delta}$ & $\mathbf{k}$ & $\mathbf{h}$ & $\boldsymbol{\beta}$ & $\boldsymbol{\tau}_{\mathrm{E} 15^{\circ} \mathbf{C}}(\mathbf{s})$ & $\mathbf{C}_{\mathbf{1}}$ & $\mathbf{C}_{\mathbf{2}}$ \\
\hline WF-4 & 100 & 36,100 & 1.39 & 0.142 & 0.49 & 250 & $4.0 \times 10^{-2}$ & 18.9 & 133.2 \\
WF-6 & 100 & 39,500 & 1.39 & 0.142 & 0.49 & 250 & $7.0 \times 10^{-2}$ & 18.9 & 133.2 \\
WF-8 & 100 & 38,500 & 1.39 & 0.142 & 0.49 & 250 & $4.0 \times 10^{-2}$ & 18.9 & 133.2 \\
GB5-3 & 100 & 39,800 & 1.17 & 0.130 & 0.442 & 250 & $5.5 \times 10^{-2}$ & 19.2 & 139.5 \\
GB5-4 & 100 & 41,100 & 1.17 & 0.130 & 0.442 & 250 & $7.0 \times 10^{-2}$ & 19.2 & 139.5 \\
GB5-4 & 100 & 40,500 & 1.17 & 0.130 & 0.442 & 250 & $7.0 \times 10^{-2}$ & 19.2 & 139.5 \\
\hline
\end{tabular}

It must be highlighted that values of constants $E_{00}$ and $\beta$ are assumed because they have no influence on the complex modulus values in the frequency range involved during the dynamic tests. The constants governing the value of the Poisson's ratio $v_{00}, v_{0}$ and $\tau_{v}$ do not appear in Tables 5 and 6 because the Poisson's ratio was not evaluated from the dynamic tests but assumptions on the values of these constants were necessary to back-calculate the complex modulus at each temperature in the first step of the first method. A good proximity between the results obtained with the two methods is shown in Figure 12. The same observation was made for all specimens. To validate this visual impression, the relative difference between the norm (in \%) and the phase (in ${ }^{\circ}$ ) of the 2S2P1D simulated complex modulus obtained from the two methods are plotted in Figure 13. In this figure, the relative difference is plotted against the reduced frequency at $15^{\circ} \mathrm{C}$ for all specimens. It is seen that the second method considering a constant complex modulus at each temperature and a constant real Poisson's ratio of 0.3 gives a norm slightly higher than the first method with a maximum relative difference of about $3.7 \%$. The phase angle determined with the two methods can be considered equivalent with less than $0.03^{\circ}$ of difference, which was expected because only constant $E_{0}$ of the 2S2P1D model differs between the first and the second method. The slight differences between the two methods may be explained by the different assumptions on the Poisson's ratio value which is modelled with the 2S2P1D model in the first method and taken constant equal to 0.3 in the second method. However, the two proposed methods are in very good agreement. This result is interesting because the second simplified method does not require in the first step the use of an elaborate LVE model. In addition, the back-calculation process is easy to perform as the two calculated constants can be identified using dichotomy process. This new simplified approach considerably reduces the computational time and offers great potential to back-calculate the complex modulus of AM from FRFs measurements using the first resonance peak only. 

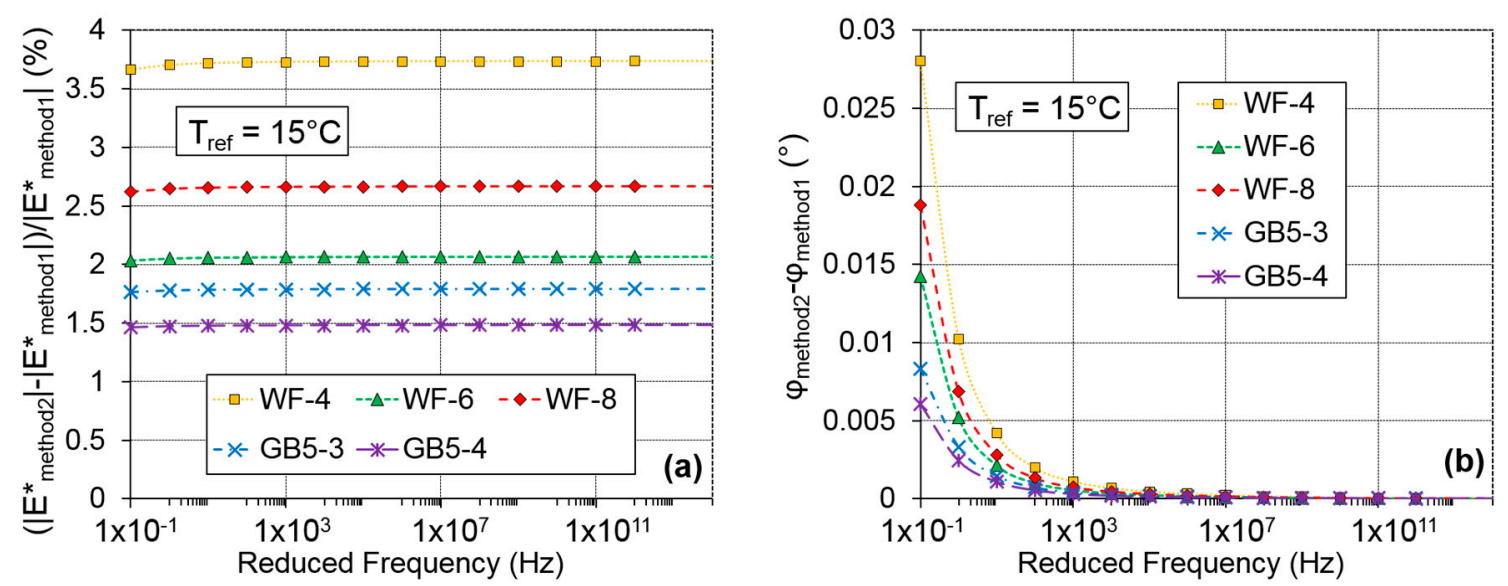

Figure 13. Difference between the complex modulus obtained from the two methods of analysis of the dynamic tests plotted at a reference temperature of $15^{\circ} \mathrm{C}$ for all specimens: (a) relative difference for the norm of the complex modulus (in \%); and (b) difference for the phase of the complex modulus $\left(\right.$ in $\left.^{\circ}\right)$.

\subsection{Comparison between Cyclic and Dynamic Tests Results}

The reduced frequency range of the tension-compression and dynamic tests is different, as confirmed in Figures 10 and 11. The tension-compression tests cover a reduced frequency range between approximately $10^{-7} \mathrm{~Hz}$ to $10^{9} \mathrm{~Hz}$ at a reference temperature of $15^{\circ} \mathrm{C}$. The dynamic tests cover a reduced frequency range between approximately $1 \mathrm{~Hz}$ and $10^{12} \mathrm{~Hz}$ at the same reference temperature of $15{ }^{\circ} \mathrm{C}$. Therefore, the best fit between the two tests is expected to be for frequencies higher than $1 \mathrm{~Hz}$ and lower than $10^{9} \mathrm{~Hz}$ for which experimental data from the two tests is available. As the two methods of back analysis of the dynamic tests give similar results, only the complex modulus obtained from the 2S2P1D model calibrated using the second method of analysis was chosen for the comparison with results of the 2S2P1D model calibrated from quasi-static tension-compression tests data. The relative difference between the norm (in \%) and the phase (in ${ }^{\circ}$ ) of the complex modulus from the two calibration processes are plotted in Figure 14 where the results are plotted against the reduced frequency at $15{ }^{\circ} \mathrm{C}$ for all specimens. It is shown in Figure 14 that the complex modulus simulated from the two tests are in quite good agreement for the high reduced frequencies $\left(>10^{7} \mathrm{~Hz}\right)$, which was expected when dealing with dynamic measurements. The norm of the dynamic complex modulus is around $3-5 \%$ higher than the norm of the complex modulus of the tension-compression tests for this frequency range and there is less than $0.2^{\circ}$ of difference between the phase angles from both tests. For lower reduced frequencies (or higher temperatures), the relative difference increases for the norm and reach a value between $12 \%$ and $30 \%$ at $1 \mathrm{~Hz}$ depending on the specimen with an average value of $20.2 \%$. The difference also increases for the phase angle but remains less than $2.5^{\circ}$ for reduced frequencies higher than $1 \mathrm{~Hz}$.

The differences observed in Figure 14 show that the dynamic complex modulus has a higher norm and a lower phase angle than the complex modulus obtained from the tension-compression tests. The differences between the two tests increase with temperature. These results are in agreement with results from previous studies using FRFs [18-21]. The differences between the two tests could be due to two phenomena. First, the level of strain applied is different in the two types of tests (about $50 \mu \mathrm{m} / \mathrm{m}$ for the tension-compression tests and about $0.1 \mu \mathrm{m} / \mathrm{m}$ for the dynamic tests). It is known that AM have a nonlinear behaviour showing a strain level dependence even at small strain amplitude [39-41]. The differences observed in this analysis are in the same direction than the observed nonlinearity: increasing of norm and decreasing of phase angle when decreasing strain amplitude. Then, nonlinearity may account for at least a part of the difference between the two tests. Another possibility is ageing of the materials. The tension-compression tests were performed several months before the dynamic tests 
and this could explain why the dynamic complex modulus is stiffer. However, the overall agreement between the two tests is satisfying.
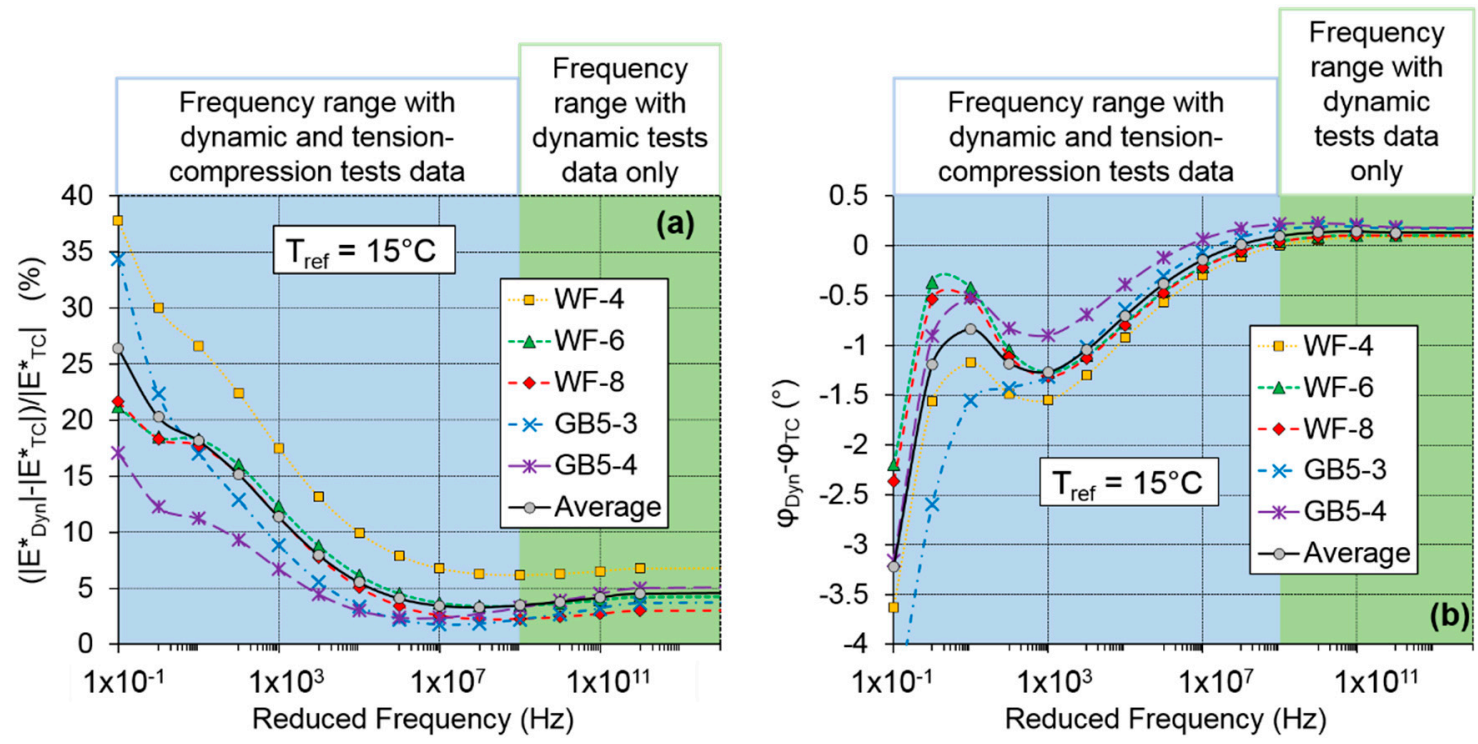

Figure 14. Relative difference between the complex modulus simulated with the 2S2P1D model calibrated from back-calculation of the dynamic tests and the complex modulus simulated with the 2S2P1D model calibrated on the data of the tension-compression tests at $15^{\circ} \mathrm{C}$ for all specimens: (a) relative difference for the norm of the complex modulus (in \%); and (b) relative difference for the phase of the complex modulus (in ${ }^{\circ}$ ).

The shift factors from the WLF equation obtained from the tension-compression tests and from the dynamic tests are plotted in Figure 15. It is seen that, for the low temperatures, the agreement between the shift factors from both tests is very good. For temperatures higher than $10^{\circ} \mathrm{C}$, the shift factors of the dynamic tests tend to be higher than the shift factors of the cyclic tests and the difference increases with temperature. The difference between the shift factors is more important for material labelled GB5. However, there is no apparent link between the difference observed in Figure 14 for the complex modulus and for the shift factors since the highest difference on the complex modulus evaluation correspond to a specimen of material labelled WF.

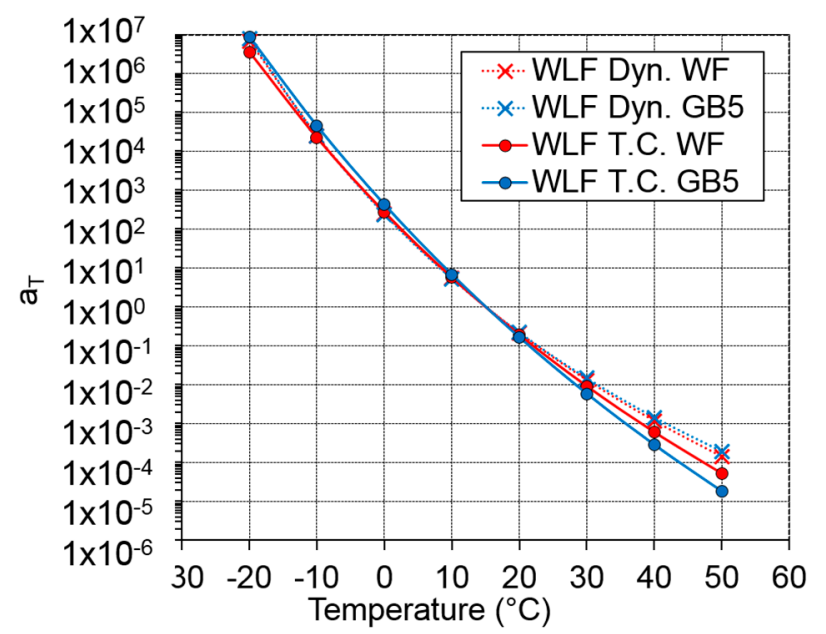

Figure 15. Shift factors of the WLF equation (Equation (7)) obtained from the tension-compression tests (WLF T.C.) and from the dynamic tests (WLF Dyn.) for the two tested materials. 


\section{Conclusions}

In this paper, conventional cyclic tension-compression tests and dynamic tests were performed to characterize the LVE behaviour of AM on a large range of frequencies and temperatures. Two different $\mathrm{AM}$ and five specimens were tested with both tests and results were analysed using the 2S2P1D model.

Two methods were studied to back-calculate the complex modulus of AM from dynamic measurements at each temperature. It is shown that the same shift factors are found with the two methods. Moreover, the two methods give very similar complex modulus values (less than $4 \%$ of difference for the norm of the modulus and $0.03^{\circ}$ for the phase angle) and the differences observes may be due to the different assumptions on the Poisson's ratio value. Therefore, the second method, which is a new and simpler approach, appears to be a good option to obtain the complex modulus of AM from FRFs.

The results of dynamic tests were also compared to the results of tension-compression tests. The shift factors from both tests are very close for the low temperatures and shift factors from dynamic tests are little higher for temperatures higher than $10^{\circ} \mathrm{C}$. The complex modulus obtained from dynamic tests have a higher norm and a lower phase angle than the ones determined with the conventional approach using cyclic tests. The differences observed between the two tests are very limited for the high frequencies or low temperatures (less than $5 \%$ for the norm and $0.2^{\circ}$ for the phase angle) and are more important for the low frequencies or high temperatures (around $20 \%$ for the norm and $2^{\circ}$ for the phase angle at $15^{\circ} \mathrm{C}$ and $1 \mathrm{~Hz}$ ). Since the strain level is approximately 500 times lower in the dynamic tests, the nonlinearity of AM with the level of strain amplitude may explain a part of the differences. Ageing of the materials between the tension-compression and the dynamic tests may also have an impact on the complex modulus evaluation.

The agreement between dynamic tests and the tension-compression tests is still satisfactory on the whole frequency range. The combination of the two tests methods is useful to improve the characterization of the LVE behaviour of AM on a wider frequency range because dynamic tests give access to very high frequencies. The presented research shows that dynamic tests, which have the great advantage of being cheap and rapid, can be back-analysed with a very simple model and can provide accurately the complex modulus of AM on a wide range of frequencies and temperatures.

Author Contributions: Methodology, J.-C.C., H.D.B., and C.S.; experimental tests, J.-C.C.; formal analysis, J.-C.C.; writing-original draft preparation, J.-C.C.; and writing-review and editing, H.D.B. and C.S.

Funding: This research received no external funding.

Conflicts of Interest: The authors declare no conflict of interest.

\section{References}

1. Di Benedetto, H.; Corte, J.F. Matériaux Routiers Bitumineux 2: Constitution et Propriétés Thermomécaniques des Mélanges; Lavoisier: Paris, France, 2005; p. 288. (In French)

2. Halvorsen, W.G.; Brown, D.L. Impulse technique for structural response frequency testing. J. Sound Vib. 1977, 11, 8-21. [CrossRef]

3. ASTM: C215-08. Standard Test Method for Fundamental Transverse, Longitudinal and Torsional Frequencies of Concrete Specimens; ASCE: West Conshoshocken, PA, USA, 2008.

4. Migliori, A.; Sarrao, J. Resonant Ultrasound Spectroscopy-Applications to Physics, Materials Measurements and Nondestructive Evaluation; Wiley-Interscience Publication: New York, NY, USA, 1997.

5. Renault, A.; Jaouen, L.; Sgard, F. Characterization of elastic parameters of acoustical porous materials from beam bending vibrations. J. Sound Vib. 2010, 330, 1950-1963. [CrossRef]

6. Di Benedetto, H.; Sauzéat, C.; Sohm, J. Stiffness of bituminous mixtures using ultrasonic wave propagation. Road Mater. Pavement Des. 2009, 10, 789-814. [CrossRef]

7. Mounier, D.; Di Benedetto, H.; Sauzéat, C. Determination of bituminous mixtures linear properties using ultrasonic wave propagation. Constr. Build. Mater. 2012, 36, 638-647. [CrossRef] 
8. Norambuena-Contreras, J.; Castro-Fresno, D.; Vega-Zamanillo, A.; Celay, M.; Lombillo-Vozmediano, I. Dynamic modulus of asphalt mixture by ultrasonic direct test. NDT E Int. 2010, 43, 629-634. [CrossRef]

9. Kweon, G.; Kim, Y.R. Determination of the complex modulus of asphalt concrete using the impact resonance test. J. Transp. Res. Board 2006, 1970, 151-160. [CrossRef]

10. Lacroix, A.; Kim, Y.R.; Far, M.S.S. Constructing the dynamic modulus mastercurve using impact resonance testing. J. Assoc. Asphalt Paving Technol. 2009, 78, 67-102.

11. Whitmoyer, S.L.; Kim, Y.R. Determining asphalt concrete properties via the impact resonant method. J. Test. Eval. 1994, 22, 139-148. [CrossRef]

12. Gudmarsson, A.; Ryden, N.; Birgisson, B. Application of resonant acoustic spectroscopy to asphalt concrete beams for determination of the dynamic modulus. Mater. Struct. 2012, 45, 1903-1913. [CrossRef]

13. Leisure, R.; Willis, F. Resonant ultrasound spectroscopy. J. Phys. Condens. Matter 1999, 9, 6001-6029. [CrossRef]

14. Ostrovsky, L.; Lebedev, A.; Matveyev, A.; Popatov, A.; Sutin, A.; Soustova, I.; Johnson, P. Application of three-dimensional resonant acoustic spectroscopy method to rock and building materials. J. Acoust. Soc. Am. 2001, 110, 1770-1777. [CrossRef] [PubMed]

15. Ryden, N. Resonant frequency testing of cylindrical asphalt samples. Eur. J. Environ. Civ. Eng. 2011, 15, 587-600. [CrossRef]

16. Ren, Z.; Atalla, N.; Ghinet, S. Optimization based identification of the dynamic properties of linearly viscoelastic materials using vibrating beam techniques. ASME J. Vib. Acoust. 2011, 133, 041012. [CrossRef]

17. Rupitsch, S.J.; Ilg, J.; Sutor, A.; Lerch, R.; Döllinger, M. Simulation based estimation of dynamic mechanical properties for viscoelastic materials used for vocal fold models. J. Sound Vib. 2011, 330, 4447-4459. [CrossRef]

18. Gudmarsson, A.; Ryden, N.; Birgisson, B. Characterizing the low strain complex modulus of asphalt concrete specimens through optimization of frequency response functions. J. Acoust. Soc. Am. 2012, 132, 2304-2312. [CrossRef] [PubMed]

19. Gudmarsson, A.; Ryden, N.; Di Benedetto, H.; Sauzéat, C.; Tapsoba, N.; Birgisson, B. Comparing Linear Viscoelastic Properties of Asphalt Concrete Measured by Laboratory Seismic and Tension-Compression Tests. J. Nondestruct. Eval. 2014, 33, 571-582. [CrossRef]

20. Gudmarsson, A.; Ryden, N.; Di Benedetto, H.; Sauzéat, C. Complex modulus and complex Poisson's ratio from cyclic and dynamic modal testing of asphalt concrete. Constr. Build. Mater. 2015, 88, 20-31. [CrossRef]

21. Carret, J.-C.; Pedraza, A.; Di Benedetto, H.; Sauzéat, C. Comparison of the 3-dim linear viscoelastic behavior of asphalt mixes determined with tension-compression and dynamic tests. Constr. Build. Mater. 2018, 174, 529-536. [CrossRef]

22. Carret, J.-C.; Di Benedetto, H.; Sauzéat, C. Multi-modal dynamic linear viscoelastic back analysis for asphalt mixes. J. Nondestruct. Eval. 2018, 37, 35. [CrossRef]

23. Poirier, J.E.; Pouget, S.; Leroy, C.; Delaporte, B. Projets Mure et Improvmure: Bilan à mi-parcours. Revue Générale des Routes et de l'Aménagement 2016, 937, 38-41. (In French)

24. Gayte, P.; Di Benedetto, H.; Sauzéat, C.; Nguyen, Q. Influence of transient effects for analysis of complex modulus tests on bituminous mixtures. Road Mater. Pavement Des. 2015, 17, 271-289. [CrossRef]

25. Graziani, A.; Di Benedetto, H.; Perraton, D.; Sauzéat, C.; Hofko, B.; Poulikakos, L.; Pouget, S. Recommendation of RILEM TC 237-SIB on complex Poisson's ratio characterization of bituminous mixtures. Mater. Struct. 2017, 50, 142. [CrossRef]

26. Perraton, D.; Di Benedetto, H.; Sauzéat, C.; Hofko, N.; Graziani, A.; Nguyen, Q. 3 Dim experimental investigation of linear viscoelastic properties of bituminous mixtures. Mater. Struct. 2016, 49, 4813-4829. [CrossRef]

27. Di Benedetto, H.; Olard, F.; Sauzéat, C.; Delaporte, B. Linear viscoelastic behavior of bituminous materials: From binders to mixtures. Road Mater. Pavement Des. 2004, 5, 163-202. [CrossRef]

28. Olard, F.; Di Benedetto, H. General 2S2P1D model and relation between the linear viscoelastic behaviors of bituminous binders and mixes. Road Mater. Pavement Des. 2003, 4, 185-224. [CrossRef]

29. Tiouajni, S.; Di Benedetto, H.; Sauzéat, C.; Pouget, S. Approximation of linear viscoelastic model in the 3 dimensional case with mechanical analogues of finite size-Application to bituminous materials. Road Mater. Pavement Des. 2011, 12, 897-930. [CrossRef]

30. Di Benedetto, H.; Delaporte, B.; Sauzéat, C. Three dimensional linear behavior of bituminous materials: Experiments and modeling. ASCE Int. J. Geomech. 2007, 7, 149-157. [CrossRef] 
31. Nguyen, H.M.; Pouget, S.; Di Benedetto, H.; Sauzéat, C. Time-temperature superposition principle for bituminous mixtures. Eur. J. Environ. Civ. Eng. 2009, 13, 1095-1107. [CrossRef]

32. Nguyen, M.L.; Sauzéat, C.; Di Benedetto, H.; Tapsoba, N. Validation of the time-temperature superposition principle for crack propagation in bituminous mixtures. Mater. Struct. 2013, 46, 1075-1087. [CrossRef]

33. Nguyen, Q.T.; Di Benedetto, H.; Sauzéat, C.; Tapsoba, N. Time-temperature superposition principle validation for bituminous mixes in the linear and nonlinear domain. ASCE J. Mater. Civ. Eng. 2013, 25, 1181-1188. [CrossRef]

34. Ferry, J.D. Viscoelastic Properties of Polymers, 3rd ed.; John Wiley \& Sons: New York, NY, USA, 1980.

35. Brüggemann, T.; Biermann, D.; Zabel, A. Development of an automatic modal pendulum for the measurement of frequency responses for the calculation of stability charts. Procedia CIRP 2015, 33, 587-592. [CrossRef]

36. Norman, P.E.; Jung, G.; Ratcliffe, C.; Crane, R.; Davis, C. Development of an Automated Impact Hammer for Modal Analysis of Structures; DSTO-TN-1062; DSTO Defence Science and Technology Organisation: Fishermans Bend, Australia, 2012.

37. Mangiafico, S.; Di Benedetto, H.; Sauzéat, C.; Olard, F.; Pouget, S.; Planque, L. New method to obtain viscoelastic properties of bitumen blends from pure and RAP binder constituents. Road Mater. Pavement Des. 2014, 15, 312-329. [CrossRef]

38. Pouget, S.; Sauzéat, C.; Di Benedetto, H.; Olard, F. Modeling of viscous bituminous wearing course materials on orthotropic steel deck. Mater. Struct. 2012, 45, 1115-1125. [CrossRef]

39. Airey, G.; Rahimzadeh, B. Combined bituminous binder and mixture linear rheological properties. Constr. Build. Mater. 2004, 18, 535-548. [CrossRef]

40. Nguyen, Q.T.; Di Benedetto, H.; Sauzéat, C. Linear and nonlinear viscoelastic behavior of bituminous mixtures. Mater. Struct. 2015, 48, 2339-2351. [CrossRef]

41. Mangiafico, S.; Babadopoulos, L.; Di Benedetto, H.; Sauzéat, C. Nonlinearity of bituminous mixtures. Mech. Time-Depend. Mater. 2018, 22, 29-49. [CrossRef]

(C) 2018 by the authors. Licensee MDPI, Basel, Switzerland. This article is an open access article distributed under the terms and conditions of the Creative Commons Attribution (CC BY) license (http:/ / creativecommons.org/licenses/by/4.0/). 